\title{
PRESERVATION OF THE OLFACTORY TRACT IN BIFRONTAL CRANIOTOMY
}

\author{
Paulo H. Aguiar', Guilherme A. Pulici², Leonardo O. Lourenco², \\ Juan A.C. Flores ${ }^{1}$, Valter A. Cescato ${ }^{1}$
}

\begin{abstract}
The bifrontal craniotomy approach used to be associated with a high percentage of olfactory tract damage. We present our experience with this technique, that was used with excellent results in a series of 11 patients that underwent the surgical approach described in this paper. We support the idea that bilateral subfrontal craniotomy allows a wide operative exposure as well as the complete anatomic and functional preservation of the olfactory tracts bilaterally.
\end{abstract}

KEY WORDS: bifrontal craniotomy, olfactory tract preservation, anterior cranial base, olfaction, surgical technique.

\begin{abstract}
Preservação do trato olfatório em craniotomias bifrontais
RESUMO - A craniotomia bifrontal costumava estar associada com alta incidência de lesão do trato olfatório. Apresentamos nossa experiência com técnica que foi usada com excelentes resultados numa série de 11 pacientes que foram submetidos à abordagem cirúrgica descrita neste estudo. Defendemos a idéia de que a craniotomia bilateral subfrontal permite uma exposição cirúrgica ampla bem como a completa preservação anatômica e funcional dos tratos olfatórios bilateralmente.
\end{abstract}

PALAVRAS-CHAVE: craniotomia bifrontal, preservação do trato olfatório, base anterior de crânio, olfato, técnica cirúrgica.

The anterior cranial base and the suprasellar and parasellar regions approach and its several methods have been described since 1981 by Suzuki et al. ${ }^{1-3}$. Extended frontal approaches, however, necessitate removal of the crista galli and sectioning of the olfactory rootlets with the associated risk of anosmia, cerebrospinal fluid (CSF) leak, and the need for complex reconstruction of the frontal floor ${ }^{4}$. Bifrontal craniotomy is the conventional approach to lesions in these locations $\mathbf{s}^{5,6}$, but its shortcoming has been the damage to the olfactory tract ${ }^{7}$.

The preservation of the olfactory tract has been the subject of many studies in extended frontal approaches. Fujiwara et al. ${ }^{7}$ and Eriksen et al. ${ }^{8}$ reported various cases of anosmia after anterior communicating artery aneurysm surgery. Spetzler et al. ${ }^{4}$ modified the technique of handling the cribriform plate to preserve the olfactory unit. Srinivasan et al. ${ }^{9}$ described the bifrontal approach that enhanced the exposure of the suprasellar region and minimized manipulation of the optic apparatus and the carotid arteries.

In our study, we present our experience with the use of bifrontal craniotomy in 11 patients with several lesions, e.g., intracerebral schwannoma, craniopharyngiomas, pituitary adenomas and Rathke Cyst. We also report the complete preservation of olfaction in these patients who underwent bifrontal craniotomy.

\section{METHOD}

Operative technique

With the patient in the supine position, the head is fixed in a three-point head-holder. The skin is incisioned posterior to the frontal hair line from zigoma to zigoma (Fig 1) and the scalp and pericranial flaps are reflected anteriorly. Two burr holes are produced on each side on the orbital buttons with a high-speed drill. Through the use of a craniotome, an osteoplastic osteotomy is performed, extending close to the orbital roof anteriorly and

1Division of Neurosurgery of Hospital das Clinicas, University of São Paulo Medical School, São Paulo SP, Brazil. ${ }^{2}$ Neurosurgical Clinic of Pinheiros, São Paulo SP, Brazil.

Received 23 May 2001, received in final form 10 September 2001. Accepted 26 September 2001. 


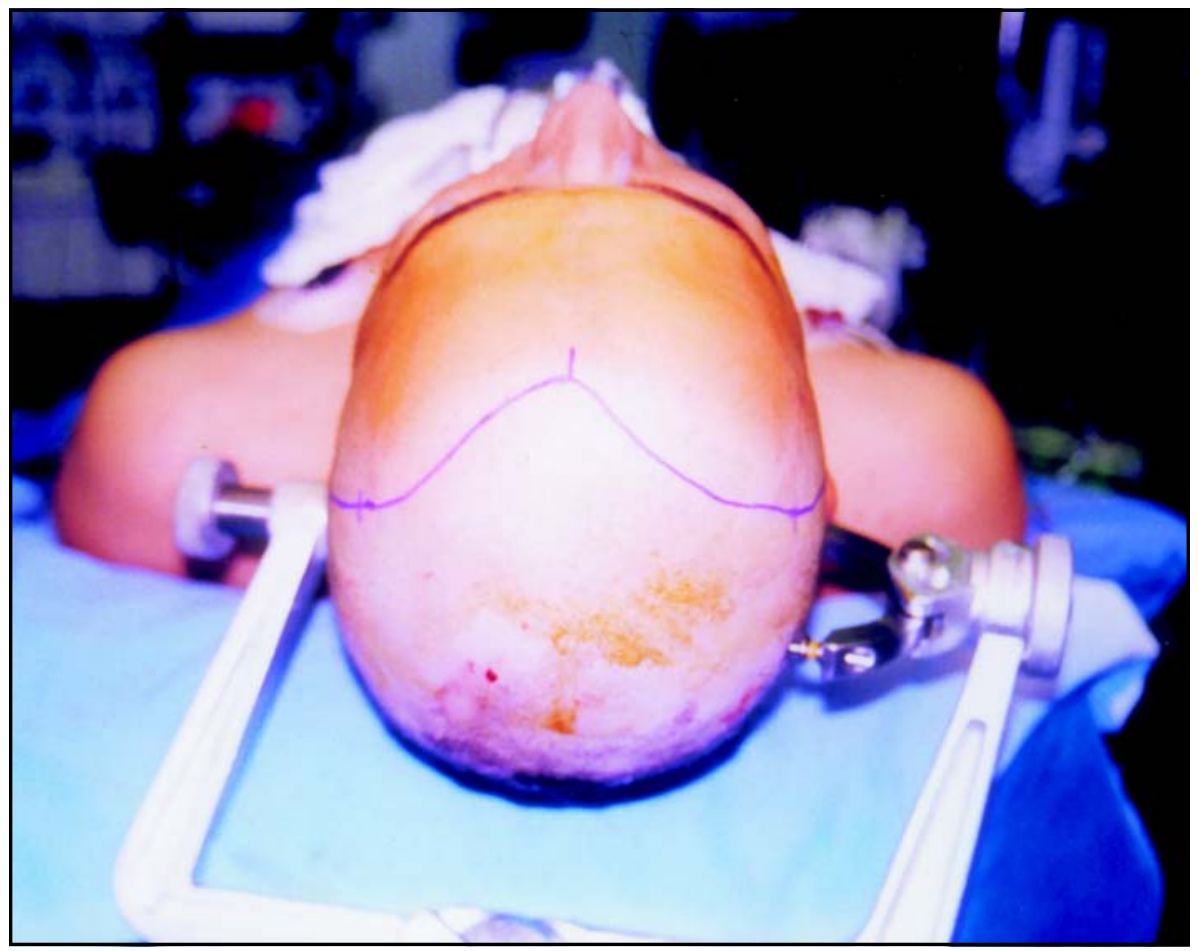

Fig 1. Case 4. Surgical view of the marked line to be incisioned.

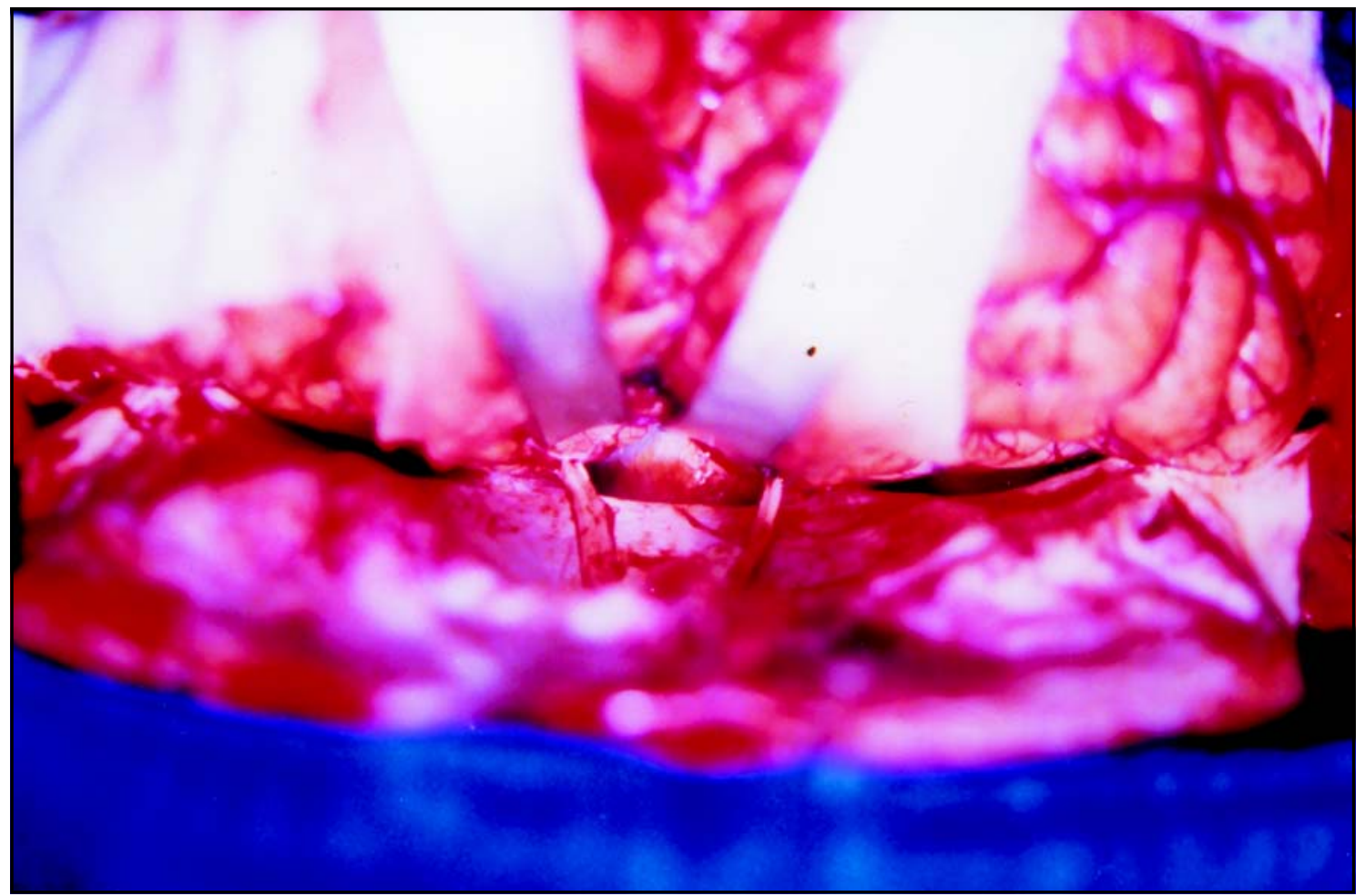

Fig 2. Case 4. Surgical view under magnification showing the retraction of the frontal poles.

along the cranium convexity posteriorly. Both frontal sinuses tables are accessed and the mucous membranes are removed. The dura mater is cut parallel to the base and the sagittal sinus is ligated and cut at the cecal fora- men. Then the falx is transected and the bridging veins are preserved. The frontal poles are retracted, under magnification, using two self-retaining retractors adjusted stepwise (Fig 2). 
Table 1. Clinical data for 11 patients with preservation of the olfactory tract.

\begin{tabular}{cccll}
\hline Case & Gender & Age (years) & Location & Pathology \\
\hline 1 & M & 24 & Left frontal fossa & Intracerebral schwannoma \\
2 & F & 54 & Sellar and parasellar & GH pituitary adenoma \\
3 & F & 35 & Left frontal fossa & Anaplasic glioma \\
4 & M & 30 & Sellar and suprasellar & Craniopharyngioma \\
5 & M & 35 & Sellar and parasellar & Non functionant pituitary adenoma \\
6 & M & 36 & Tubercle sellar & Meningioma \\
7 & M & 20 & Sellar and suprasellar & Craniopharyngioma \\
8 & M & 5 & Sellar and suprasellar & Rathke cyst \\
9 & F & 61 & Sellar and suprasellar & Non functionant pituitary adenoma \\
10 & F & 63 & Hypothalamus & GBM \\
11 & F & 52 & Sellar and suprasellar & Non functionant pituitary adenoma \\
\hline
\end{tabular}

The interhemispheric and the bilateral olfactory cisternae are opened in order to drain the CSF and to avoid more retraction. Both olfactory nerves should be dissected simetrically without coagulation under small bleedings.

Surgicel ${ }^{\circledR}$ is enough to stop the small bleedings mainly near the crivous plate of ethmoidal bone.

After that, the surgical overview could better show the image of both olfactory nerves and both optic nerves composing a groove enlarged by the tumor. The pseudocapsula of the tumor could be seen through this groove and the dissection between the carotid artery and the pseudocapsula should be performed on both sides. Following this step, a debulking of the tumor should be done and a "piece meal" resection is recommended.

The ultrasonic aspirator could be used with extreme caution. The retraction of bilateral frontal poles should never be strong enough to hurt the pia-mater and make damage to the brain parenchyma ${ }^{1}$.

\section{Patient population}

The surgical technique described was applied in the treatment of the 11 patients, as shown in Table 1. Of the 11 patients, 5 were female and 6 were male, with a mean age of 37.7 years (range, 5-63 yr). Histological examination revealed four adenomas (Figs 3, 4, 7, 8, 9), two craniopharyngiomas (Figs 5, 6), one GBM, one anaplasic glioma, one meningioma, one Rathke cyst, and one Schwannoma. The symptoms at admission were typical for each pathological condition, and the lesions were all totally removed by using a bilateral subfrontal approach. All these patients were preoperatively evaluated with non-enhanced and enhanced magnetic resonance tomography. Prospectively, we evaluated the clinical findings at the presentation, operative treatment, and outcome of each patient.

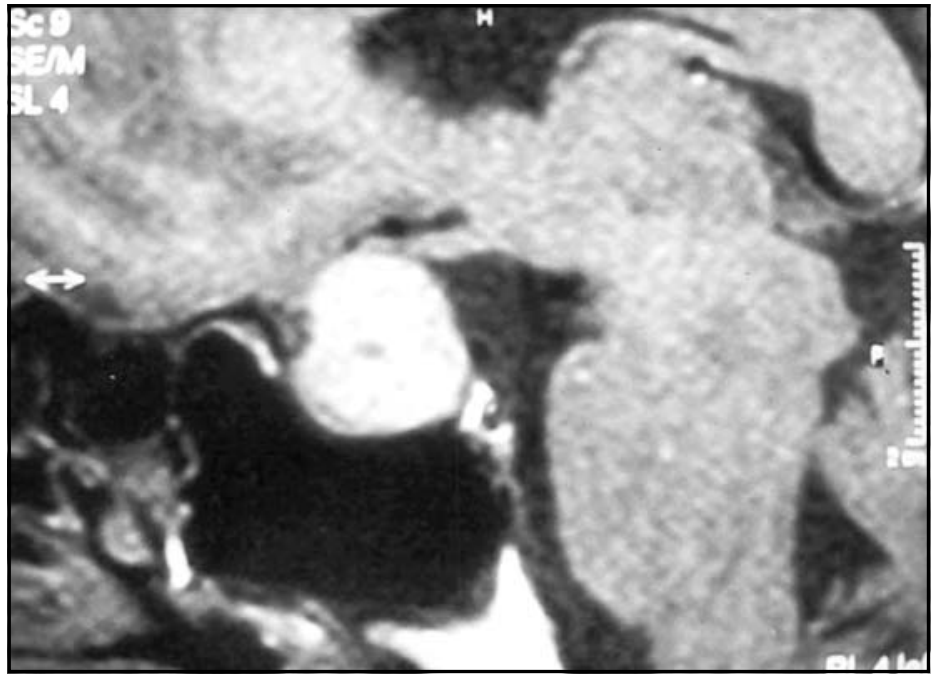

Fig 3. Case 2. Preoperative MRI of a 54-year-old female with GH pituitary macroadenoma.

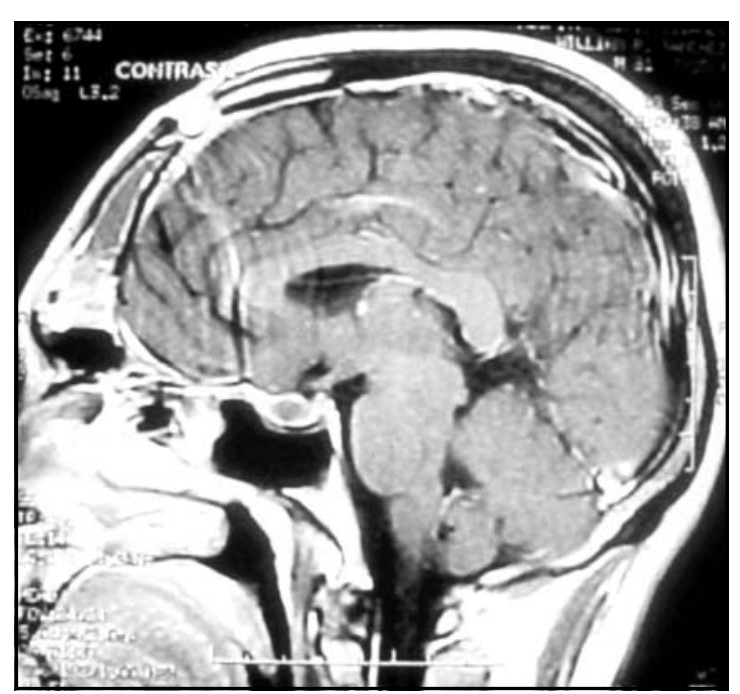

Fig 4. Case 2. Postoperative MRI of the same 54-year-old female patient showing total resection of the tumor. 


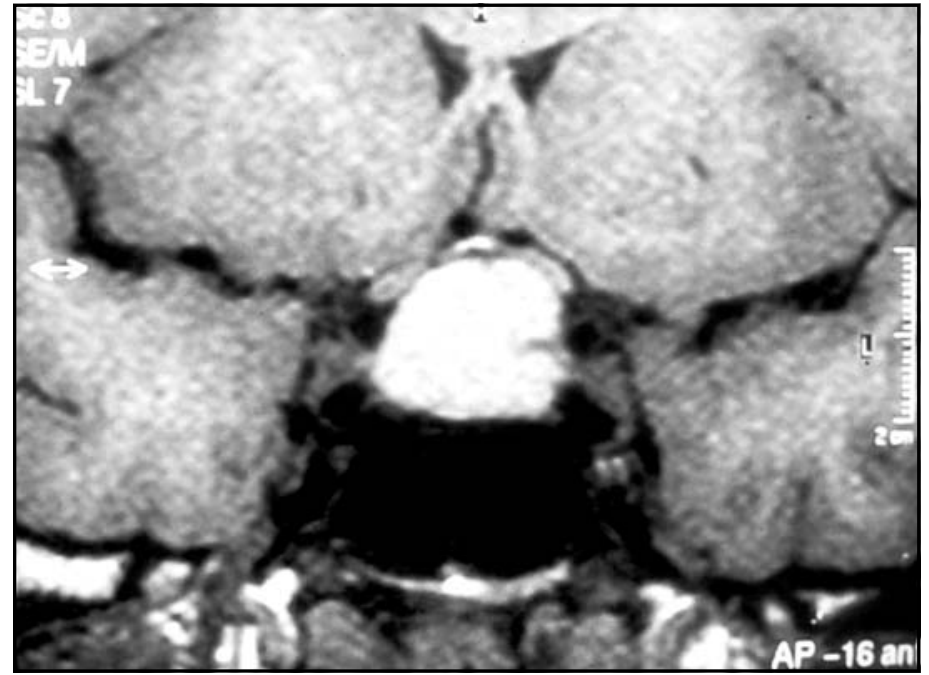

Fig 5. Case 4. Preoperative MRI of a 50-year-old male with craniopharyngioma.

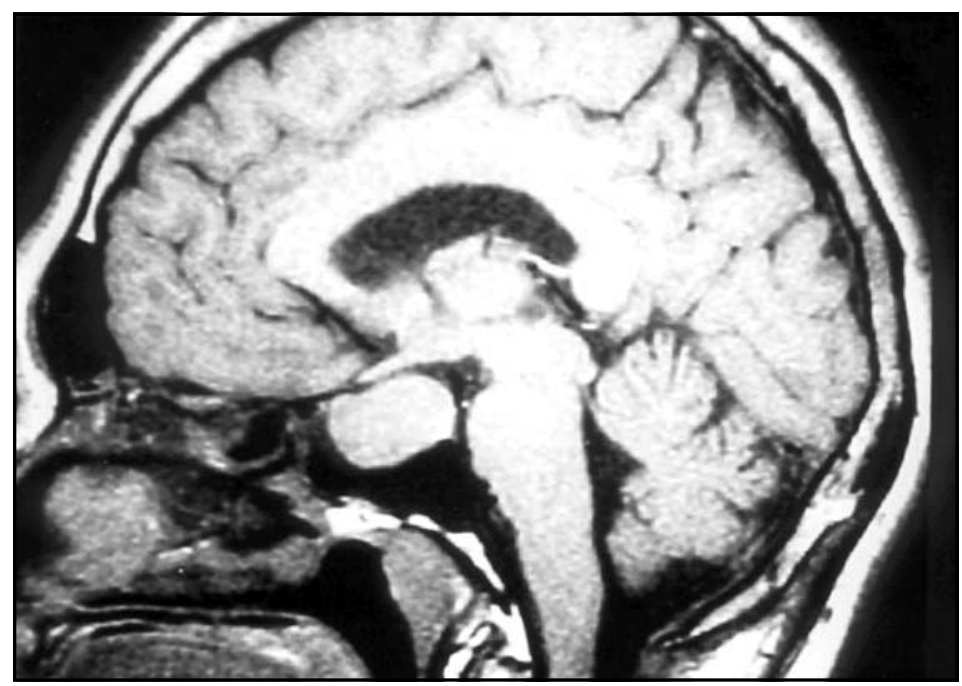

Fig 7. Case 9. Preoperative MRI of a 61-year-old female with nonfunctioning pituitary adenoma.

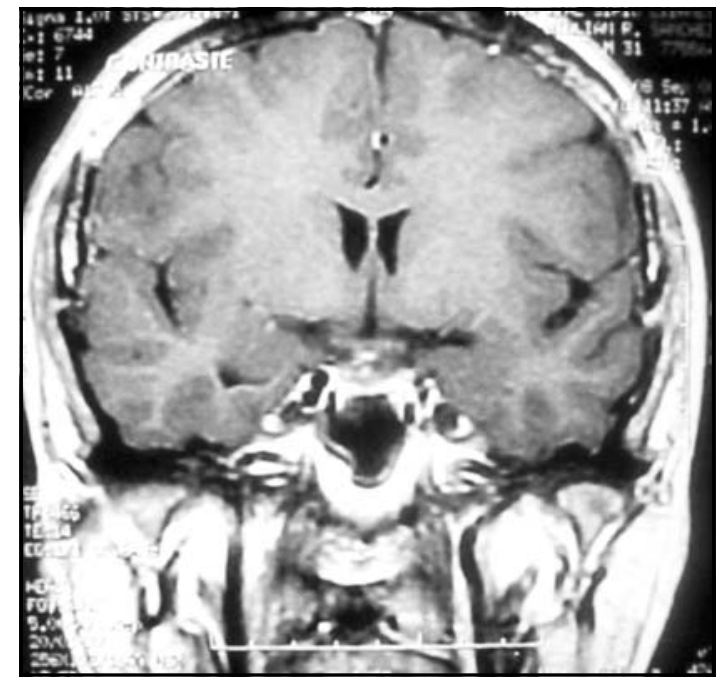

Fig 6. Case 4. Postoperative MRI of the same 50-year-old male patient showing total resection of the tumor.

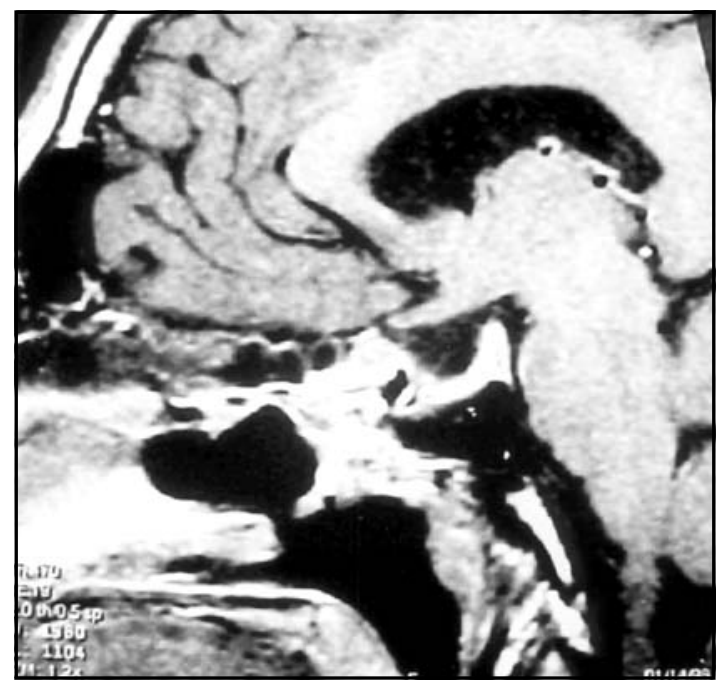

Fig 8. Case 9. Postoperative MRI of the same 61-year-old female patient after total resection of the tumor.

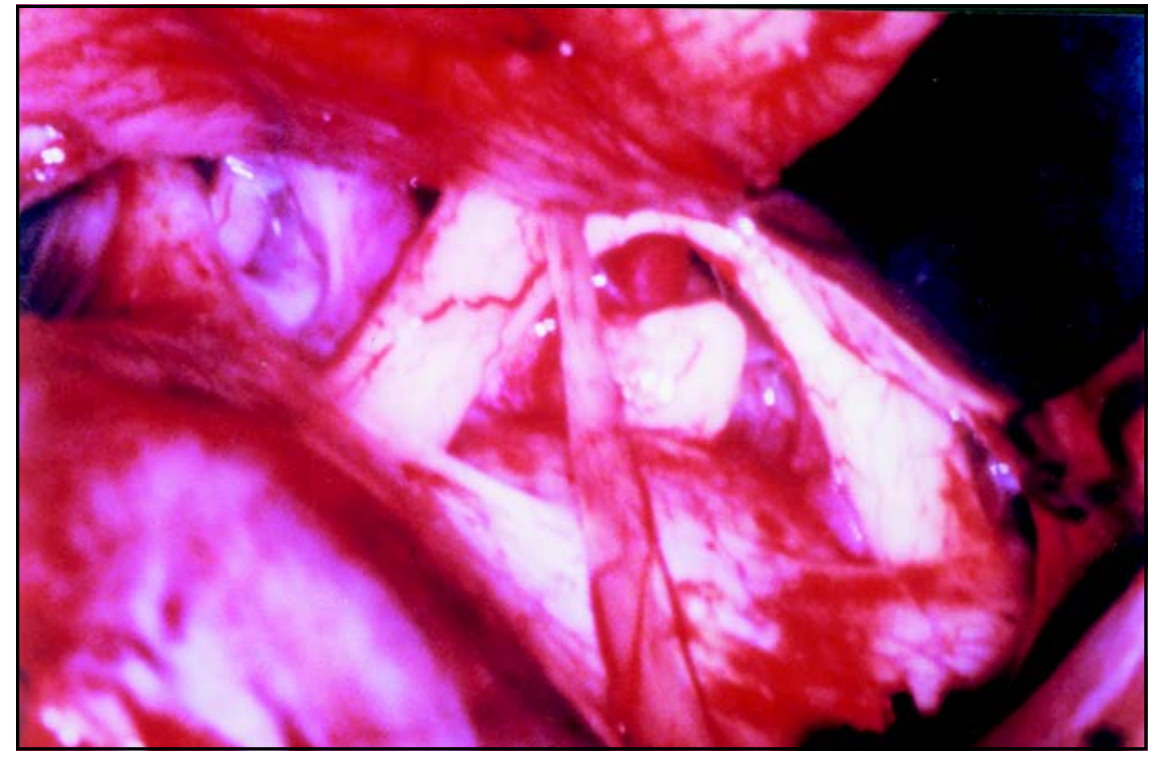

Fig 9. Case 9. Surgical view showing the olfactory nerve, the optic nerve and the left carotid artery. 


\section{RESULTS}

In our study there were no deaths or, even, clinical or surgical complications. We did not register any case of anosmia. Neurological examination made postoperatively did not reveal anything new in the 11 patients, except that they did have their olfactory tract preserved bilaterally. No subjective or objective olfactory disturbances were noted in the follow-up of those 11 patients.

\section{DISCUSSION}

In our opinion, olfaction is an extremely important neurological function, to the point that its damage can impair any individual's quality of life. Olfactory tract damage used to be regarded as the major drawback of bifrontal craniotomy $y^{2,10,11}$. Knowing that it is fundamental to preserve the anatomy and the function of both olfactory tracts, we strongly recommend the technique described above and first reported by Samii et al. ${ }^{1,12}$.

The bilateral subfrontal approach allows a good overview of the sellar, suprasellar, presellar, parasellar and the anterior cranial fossa region and permits the complete preservation of olfaction. Bifrontal craniotomy is the ideal approach to various midline lesions of those areas, as sometimes a unilateral extended pterional approach is insufficient for adequate treatment of the lesion. We are aware that this technique requires patience and time, which, in our impression is fully rewarded by its technique advantages of excellent field exposure and preservation of the olfactory tracts.
From our point of view, we strongly agree with the impressions and findings of Sepehrnia et al. ${ }^{6}$. The excellent outcome found in our series as well as in Sepehrnia et al. ${ }^{6}$ series support the good usefulness of the bilateral subfrontal craniotomy with section of the falx.

\section{REFERENCES}

1. Bini W, Sepehrnia A, Samii M. Some technical considerations regarding craniopharyngioma surgery: the bifrontal approach. In Samii M (ed). Surgery of the sellar region and paranasal sinuses. Berlin: SpringerVerlag 1991:381-386.

2. Suzuki J, Yoshimoto T, Mizoi K. Preservation of the olfactory tract in bifrontal craniotomy for anterior communicating artery aneurysms, and the functional prognosis. J Neurosurg 1981;54:342-345.

3. Yasui N, Nathal E, Fujiwara H, Suzuki A. The basal interhemispheric approach for acute anterior communicating artery aneurysms. Acta Neurochir (Wien) 1992;118:91-97.

4. Spetzler RF, Herman JM, Beals S, Joganic E, Milligan J. Preservation of olfaction in the anterior craniofacial approaches. J Neurosurg 1993;79:48-52.

5. Sekhar LN, Nanda A, Sen CN. The extended frontal approach to tumors of the anterior, middle, and posterior skull base. J Neurosurg 1992;76:198-206.

6. Sepehrnia A, Knopp U . Preservation of the olfactory tract in bifrontal craniotomy for various lesions of the anterior cranial fossa. Neurosurgery 1999;44:113-117.

7. Fujiwara H, Yasui N, Nathal-Vera E, Suzuki A. Anosmia after anterior communicating artery aneurysm surgery: comparison between the anterior interhemispheric and basal interhemispheric approaches. Neurosurgery 1996;38:325-328.

8. Eriksen KD, Boge-Rasmussen T, Kruse-Larsen C. Anosmia following operation for cerebral aneurysms in the anterior circulation. J Neurosurg 1990;72:864-865.

9. Srinivasan J, Dailey AT, Berger MS. The bifrontal olfactory nerve-sparing approach to lesions of the suprasellar region in children. Pediatr Neurosurg 1999;30:245-252.

10. Fujitsu K, Sekino T, Sakata K, Kawasaki T. Basal interfalcine approach through a frontal sinusostomy with vein and nerve preservation. J Neurosurg 1994;80:575-579.

11. Pool JL.Aneurysms of the anterior communicating artery: bifrontal craniotomy and routine use of temporary clips. J Neurosurg 1961;18:98-111.

12. Samii M. Olfactory nerve. In Samii M, Janetta PJ (eds). The cranial nerves. Berlin: Springer-Verlag 1981:69-73. 